\title{
Study on ultimate strength of ship's hull considering cross section and beam finite element.
}

\author{
Muhammad Zubair Muis Alie ${ }^{1, *}$,Juswan ${ }^{1}$, Wahyuddin $^{1}$, and Taufiqur Rachman ${ }^{1}$ \\ ${ }^{1}$ Hasanuddin University, Engineering Faculty, Department of Ocean Engineering, 92172 Gowa, South \\ Sulawesi, Indonesia
}

\begin{abstract}
The objective of the present research is to study the ultimate strength of ship's hull considering cross section and beam finite element under longitudinal bending. The single hull bulk carrier and double hull oil tanker are taken to be analysed. The one-frame space of ship is considered in the calculation. The cross section of ship's hull is divided into element composed plate and stiffened plate. The cross section is assumed to be remained plane and the simply supported is imposed to both side of the cross section. The longitudinal bending moment is applied to the cross section for hogging and sagging condition. The Smith's method is adopted and implemented into the in-house program of the cross section and beam finite element to calculate the ultimate strength of ship's hull. The result of the ultimate strength for hogging and sagging condition obtained by considering the cross section and beam finite element is compared with one another.
\end{abstract}

\section{Introduction}

A ship hull for intact condition will against applied loads smaller than the design loads. Cargo loading also acting during voyage, so that the combination between environmental and cargo loading may have an impact to structural damage such grounding, collision, cracks etc. The ultimate strength of ship hull is one of the most important aspects in the ship design criteria. The element of supporting of hull cross section must be adequate against the external forces during voyages. Otherwise, the failure of the ship's hull girder will occur and collapse may happen. Therefore, the analysis of ship's hull girder must be conducted.

The ultimate strength of ship hull girder has been analysed by some researchers. Cui 2016 [1] focused on the ultimate strength of typical bottom structure in container ships under both longitudinal and transversal loads in corrosive environment. Muis Alie, M.Z et al 2017 [2] assessed the ultimate hull girder strength of Ro-Ro ship after damage. The cross section of Ro-Ro ship is considered to be analysed. Muis Alie, M.Z et al 2016 [3] analysed the hull girder ultimate strength of asymmetrically damaged ships using Finite Element Method. The collision damage was modelled by removing the plate and stiffened plate elements. Muis Alie, M.Z et al 2014 [4] analysed the residual strength of ship hull girder with bottom damage. The nonlinear finite element method was used and the fully cross section was considered in the calculation. Shu, Z 2012 [5] investigated the ultimate strength of a capsize bulk carrier hull girder under combined global and local load in the hogging and alternate hold loading (AHL) condition using nonlinear finite element (FE) analysis with ABAQUS. Amlashi, H.K.K 2008 [6] contributed to establish rational ultimate longitudinal strength criteria for the hull girder under combined loading. An important issue

* Corresponding author: zubair.m@eng.unhas.ac.id 
was the significant double bottom bending in empty holds in AHL due to combined global hull girder bending moment and local loads. Paik, J.K 2001 [7] investigated the ultimate strength characteristics of ship hulls with large hatch opening under torsion. Axial (warping) as well as shear stress is normally developed for thin-walled beams with open cross sections subjected to torsion.

In the present paper, the ultimate strength of ship's hull considering cross section and beam finite element under longitudinal vertical bending moment is studied. The single hull bulk carrier and double hull oil tanker are taken to be analysed. The one-frame space of ship is considered in the calculation. The cross section of ship's hull is divided into elements composed plate and stiffened plate. The cross section is assumed to be remained plane and the simply supported is imposed to both side of the cross section. The longitudinal bending moment is applied to the cross section for hogging and sagging condition. The Smith's method is adopted and implemented into the in-house program of the cross section and beam finite element to calculate the ultimate strength of ship's hull. The result of the ultimate strength for hogging and sagging condition obtained by considering the cross section and beam finite element is compared with one another.

\section{Cross Section Approach}

The ultimate strength of ship hull is performed using the Smith's method considering the cross sectional approach. The in-house program code HULLST developed by Yao and Nikolov [8] is used with some modification in subroutine program. The moment-curvature relationship for the ultimate hull girder strength calculation is expressed by,

$$
\left\{\begin{array}{c}
\Delta P \\
\Delta M_{H} \\
\Delta M_{V}
\end{array}\right\}=\left[\begin{array}{lll}
\bar{D}_{A A} & \bar{D}_{A V} & \bar{D}_{A H} \\
\bar{D}_{H A} & \bar{D}_{H H} & \bar{D}_{H V} \\
\bar{D}_{V A} & \bar{D}_{V H} & \bar{D} V V
\end{array}\right]\left\{\begin{array}{c}
\Delta \varepsilon_{0} \\
\Delta \varphi_{H} \\
\Delta \varphi_{V}
\end{array}\right\}
$$

Where

$$
\begin{gathered}
\bar{D} A A=\sum_{i=1}^{N} D_{i} A_{i} \\
\bar{D} H H=\sum_{i=1}^{N} D_{i} y_{i}^{2} A_{i} \\
\bar{D} V V=\sum_{i=1}^{N} D_{i} z_{i}^{2} A_{i} \\
\bar{D} A H=\bar{D} H A=\sum_{i=1}^{N} D_{i} y_{i} A_{i} \\
\bar{D}_{A V}=\bar{D}_{V A}=\sum_{i=1}^{N} D_{i} z_{i} A_{i} \\
\bar{D}_{H V}=\bar{D}_{V H}=\sum_{i=1}^{N} D_{i} y_{i} z_{i} A_{i}
\end{gathered}
$$

To obtain the ultimate hull girder moment capacity, the above expression can be simply expressed by, 


$$
\left\{\begin{array}{c}
0 \\
\Delta M_{H} \\
\Delta M_{V}
\end{array}\right\}=\left[\begin{array}{ccc}
\bar{D}_{A A} & 0 & 0 \\
0 & \bar{D}_{H H} & \bar{D}_{H V} \\
0 & \bar{D}_{V H} & \bar{D}_{V V}
\end{array}\right]\left\{\begin{array}{c}
\Delta_{0} \\
\Delta \phi_{H} \\
\Delta \phi_{V}
\end{array}\right\}
$$

Where

$$
\begin{gathered}
\bar{D}_{A A}=\sum_{i=1}^{N} D_{i} A_{i} \\
\bar{D}_{H H}=\sum_{i=1}^{N} D_{i}\left(y_{i}-y_{G}\right)^{2} A_{i} \\
\left.\bar{D}_{H V}=\bar{D}_{V H}=\sum_{i=1}^{N} D_{i}\left(y_{i}-y_{G}\right) z_{i}-z_{G}\right) A_{i} \\
\bar{D}_{V V}=\sum_{i=1}^{N} D_{i}\left(z_{i}-z_{G}\right){ }_{i}
\end{gathered}
$$

\section{Beam Finite Element Method}

The other approach to calculate the ultimate hull girder strength of ship hull is beam finite element method. Basically, the calculation based on the fundamental of thin-walled beam theory by considering warping effect. The Smith's method is also adopted and implemented into the in-house program with some of the subroutines are combined with HULLST to generate the cross section becomes beam finite element. The formulation of the beam finite element method to analyze the ultimate hull girder strength may be calculated by,

$$
\begin{aligned}
& \left\{\begin{array}{c}
\sigma_{z} \\
\tau_{s z}
\end{array}\right\}=\left[\begin{array}{ll}
d_{11} & d_{12} \\
d_{21} & d_{22}
\end{array}\right]\left\{\begin{array}{c}
\varepsilon_{z} \\
\gamma_{s z}
\end{array}\right\} \\
& \left(\begin{array}{c}
\varepsilon_{z} \\
\gamma_{S z}
\end{array}\right)=\left[\begin{array}{cccc}
{\left[B_{1}\right]} & -x\left[B_{2}\right] & -y\left[B_{3}\right] & \omega_{n s}\left[B_{2}\right. \\
0 & 0 & 0 & g(s)\left[B_{3}\right.
\end{array}\right]\{d\}
\end{aligned}
$$

Where

$$
\begin{gathered}
{\left[B_{1}\right]=\frac{d}{d z}\left[A_{L}\right]} \\
{\left[B_{2}\right]=\frac{d^{2}}{d z^{2}}\left[A_{C}\right]} \\
{\left[B_{3}\right]=\frac{d}{d z}\left[A_{C}\right]} \\
g(s)=\frac{\partial \omega_{n s}}{\partial s}-\left(y-y_{s}\right) \frac{\partial x}{\partial s}+\left(x-x_{s}\right) \frac{\partial y}{\partial s}
\end{gathered}
$$




$$
[K]=\int_{V}\left[\begin{array}{cccc}
d_{11}\left[B_{1}\right] & -x d_{11}\left[B_{12}\right] & -y d_{11}\left[B_{12}\right] & \omega_{n s} d_{11}\left[B_{12}\right] \\
-x d_{11}\left[B_{21}\right] & x^{2} d_{11}\left[B_{2}\right] & x y d_{11}\left[B_{2}\right] & -x \omega_{n s} d_{11}\left[B_{2}\right] \\
-y d_{11}\left[B_{21}\right] & x y d_{11}\left[B_{2}\right] & y^{2} d_{11}\left[B_{2}\right] & -y \omega_{n s} d_{11}\left[B_{2}\right] \\
\omega d_{11}\left[B_{21}\right] & -x \omega_{n s} d_{11}\left[B_{2}\right] & -y \omega_{n s} d_{11}\left[B_{2}\right] & \omega_{n s}^{2} d_{11}\left[B_{2}\right]+g^{2} d_{22}\left[B_{3}\right]
\end{array}\right]
$$

\section{Results and Discussions}

The Smith's method is adopted for the calculation of the ultimate strength of ship's hull under longitudinal bending moment. The one-frame space of ship is considered to be analyzed. The simpy supported of boundary condition is applied to both side of the cross section and beam finite finite element. The welding residual stress, initial imperfection and crack are not considered in the analysis. To know the ultimate strength of ship hull by considering the cross sectional approach and beam finite element method, the intact condition is taken. The sample of the ships are the single hull bulk carrier consists of Ship B1 and Ship B2 as shown in fig. 1, and double hull oil tanker in fig. 2. Ship B1 and Ship B2 for single hull bulk carrier have different dimension also the number of element. The boundary condition is assumed to be simply supported at both side for cross sectional approach and beam finite element method as illustrated in fig. 3 .

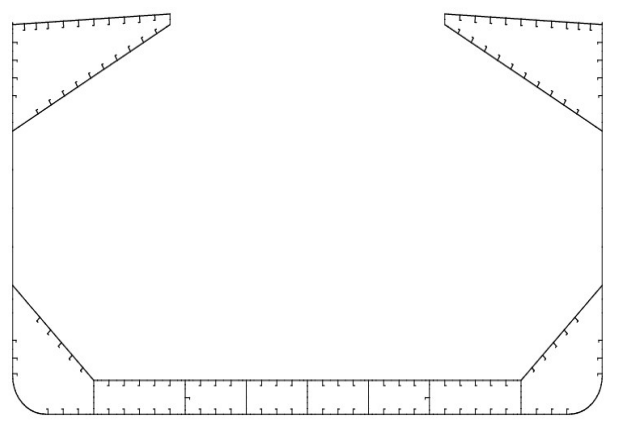

(a) Ship B1

Fig. 1. Single Hull Bulk Carrier

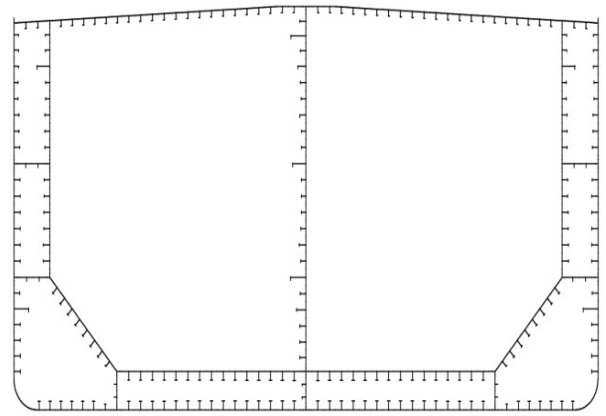

Fig. 2. Double Hull Oil Tanker

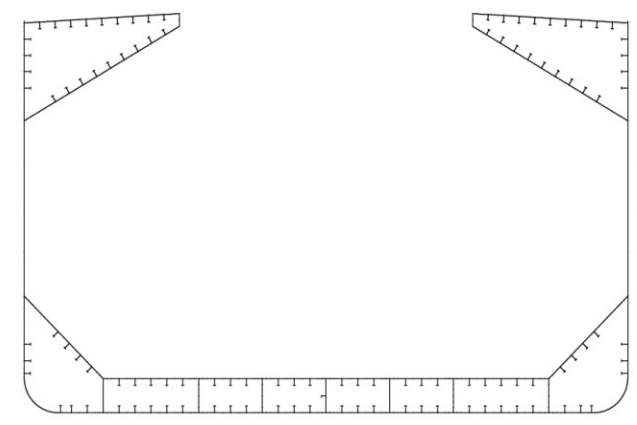

(b) Ship B2

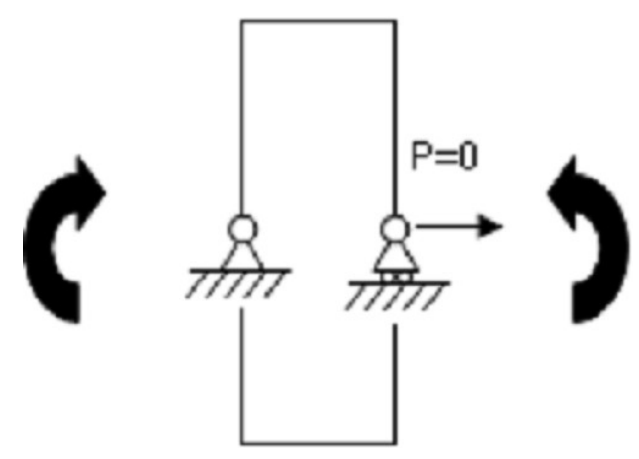

Fig. 3. Boundary Condition 


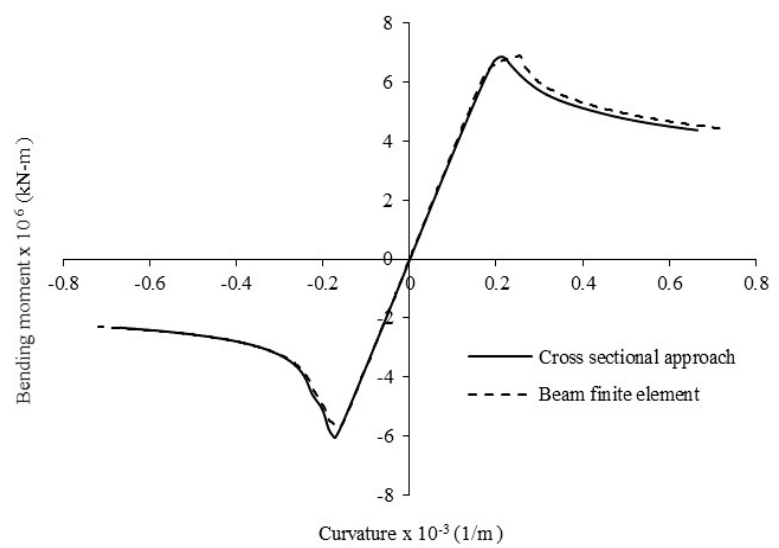

(a) Ship B1



(b) Ship B2

Fig. 4. Moment-curvature relationship for single hull bulk carrier

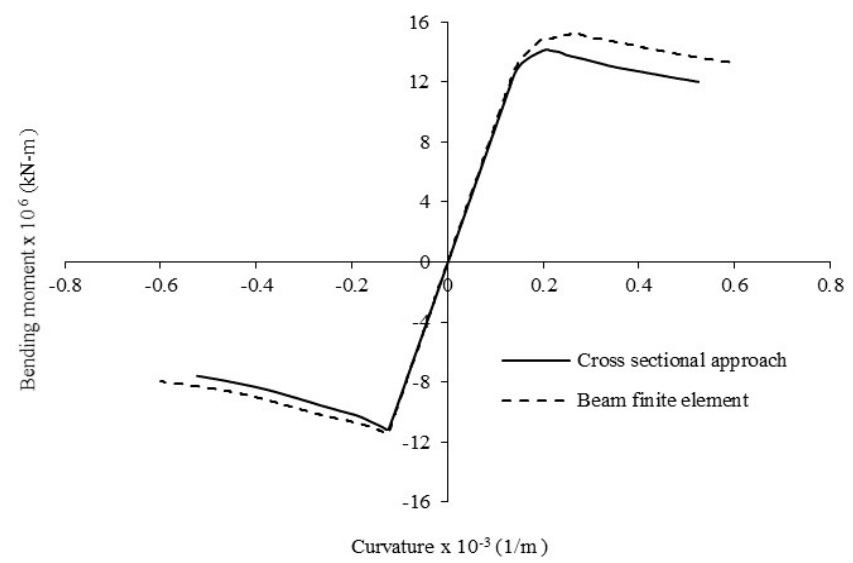

Fig. 5. Moment-curvature relationship for double hull oil tanker 
The moment-curvature relationship for ship B1 and ship B2 is expressed in fig. 4. The solid line describe the ultimate strength obtained by cross sectional approach and dot one produced by beam finite element. It is observed that the ultimate strength obtained by cross sectional approach and beam finite element is almost identic both ship B1 and ship B2 in hogging and sagging condition.

Fig. 5 shows the moment-curvature relationship for double hull oil tanker. It is observed that the ultimate strength in hogging condition is larger than sagging condition. Probably, this may due to the element component, element type and number of element of the deck part is quite different with bottom part since the deck is tension and bottom is compression.

\section{Results and Discussions}

The ultimate strength obtained by cross sectional approach and beam finite element is in good aggreement both ship B1 and ship B2 in hogging and sagging condition. For double hull oil tanker, the ultimate strength in hogging condition is larger than sagging condition. Probably, this may due to the element component, element type and number of element of the deck part is quite different with bottom part since the deck and bottom parts are in tension and compression, respectively.

\section{References}

1. Cui, J. Wang, D. Ma, N. Proc. 27th Int Offshore and Polar Eng Conf, ISOPE, 990-997, 2016.

2. Muis Alie, M.Z, Sitepu G, and Latumahina, S.I, Proc. 27th Int Offshore and Polar Eng Conf, ISOPE, 913-919, 2017.

3. Muis Alie, M.Z, Sitepu G, Juswan, Wahyuddin, Nugraha, A.M and Alamsyah," Proc. 35th Int Conf. on Ocean, Offshore and Arctic Engineering, OMAE, 2016.

4. Muis Alie, M.Z, Proc. 3rd Int Conf. on Ship and Offshore Technology, ICSOT, 1-4, 2014.

5. Shu, Z and Moan, T, J. Mar Sci. Technol, 94-113, 2012

6. Amlashi H, K.K and Moan, T, Marine Structures, 327-352, 2008.

7. Paik, J.K, Thayamballi, A.K, Pedersen, P.T and Park, Y.K, Ocean Engineering, 10971133, 2001.

8. Yao, T and Nikolov, P.I, J. Soc. Naval Arch of Japan, 437-446, 1992. 